\title{
Da intolerância religiosa no Brasil e suas perspectivas de desarmamento: uma proposta ecumênica
}

\author{
On religious intolerance in Brazil and its \\ perspectives of disarmament: \\ an ecumenical proposal
}

Mônica Baptista Campos

\section{Resumo}

A observação do censo religioso ao longo das últimas décadas demonstra que o Brasil está cada vez mais plural em termos de configuração religiosa. Houve redução significativa no número de católicos e um aumento das igrejas pentecostais. Percebe-se também uma disposição do indivíduo à experimentação, configurando assim um cenário propício à mobilidade religiosa e à dupla ou tripla pertença. Contudo, apesar dessa abertura a novas experimentações, também estamos observando uma crescente onda de intolerância religiosa no cenário brasileiro. A intolerância religiosa no Brasil é quase uma exclusividade das igrejas neopentecostais. E, geralmente, a palavra de ódio é destinada às religiões de matriz africanas. Vários segmentos da sociedade, como ONGs, coletivos, grupos de direitos humanos, associações religiosas, entre outros estão sensibilizados e atentos à questão da crescente intolerância. Há grupos que se articulam em prol da promoção da paz, e muitas vezes adquirem um veio profético junto à sociedade quando denunciam as injustiças das estruturas sociais. Em uma sociedade pluralista e neoliberal, a teologia deve buscar caminhos que promovam a boa convivência humana, a prática de uma cidadania consciente, a inclusão dos marginalizados e a justiça como um bem comum. Contudo, deve também estar conectada à fonte, à tradição, aos Evangelhos e a Jesus Cristo. Assim, estará sendo fiel à sua essência podendo contribuir para a 
construção de relações mais humanizadas, comunicando a Boa Nova, fazendo diferença em um mundo que é ameaçado pela indiferença ou o ódio ao outro. Nesta comunicação, faremos uma pequena análise da intolerância religiosa presente no Brasil, depois lançaremos luzes sobre a questão através do Evangelho e, por fim, apresentaremos uma proposta de caminhada ecumênica para deslegitimar atitudes intolerantes.

Palavras-chave: Intolerância religiosa. Ecumenismo. Neopentecostalismo. Religiões.

\section{Abstract}

The religion census of Brazil has showed a more plural religious configuration of society in the last decades. There has been a significant reduction in the number of catholics and an increase in pentecostal churches. Also, one can perceive a disposition of the individual for experimentation, thus figuring a favourable scenery of religious mobility as well as a double or triple belonging. Though there is such an opening to new experimentations, we can also observe an ongoing wave of religious intolerance in the Brazilian scenery. Religious intolerance in Brazil is almost an exclusiveness of neo-pentecostal churches. Usually the word of hate is aimed at religions of African origin. Several organizations of society, such as NGO's, human right groups, religious associations among others are moved and attentive to the issue of ongoing intolerance. There are groups that are arguing in favor of the promotion of peace, and often get a prophetic vein in society when they denounce the injustice of social structures. In a plural and neoliberal society, theology must look for ways of promoting a good human companionship, the practice of a conscious citizenship, the inclusion of the marginalized and justice as a common good. However, it also has to be connected to the source, to tradition, to the Gospels and to Jesus Christ. Thus, it will remain faithful to its essence as well as contribute to the construction of more humanized relationships, sharing the Good News, making a difference in a world threatened by indifference or the hate towards the other. In this paper, we will undertake a small analysis of religious intolerance in Brazil, and then cast light on the issue through the Gospel and, at last, present a proposal of an ecumenical way to deprive intolerant attitutes of legitimization.

Keywords: Religious intolerance. Ecumenism. Neo-pentecostalism. Religions. 


\section{Introdução}

Estamos observando uma crescente onda de intolerância religiosa no cenário brasileiro. A mídia nacional serve de referência para indicarmos alguns exemplos: "A cada 3 dias, governo recebe uma denúncia de intolerância religiosa", "Intolerância religiosa afasta professora de escola na Praça Seca, na Zona Oeste" "2 "RJ tem o $2^{\circ}$ maior número de casos de intolerância religiosa do país" . Contudo, longe de ser um problema que afeta somente a democracia brasileira, é também uma questão mundial - "Estudo diz que intolerância religiosa aumentou no mundo" ". Não só a mídia, mas também o filósofo Elie Wiesel, Prêmio Nobel da Paz (1986), afirma: "a intolerância não para de crescer em todo o mundo. Religiosa, racial ou étnica, sua disseminação põe em questão todas as vitórias reais conseguidas pelo que ainda chamamos de a civilização moderna"s.

Aumentou, porque sempre esteve presente na história da humanidade: os cristãos foram perseguidos e mortos por Nero, os hereges foram queimados na Inquisição, o genocídio armênio - relembrado recentemente pelo Papa Francisco $^{6}$ - exterminou mais de 1,5 milhão de pessoas e o holocausto dos judeus na Segunda Guerra são alguns exemplos que a história nos mostra.

O Brasil possui uma realidade cultural e social complexa e a religiosida-

\footnotetext{
${ }^{1}$ SANT'ANNA, Emilio. "A cada 3 dias, governo recebe uma denúncia de intolerância religiosa". Jornal Folha de São Paulo. Disponível em: <http://www1.folha.uol.com.br/cotidiano/2015/06/1648607-a-cada-3-dias-governo-recebe-uma-denuncia-de-intolerancia-religiosa. shtml>. Acesso em 02 de julho de 2015.

${ }^{2}$ SEÇÃO Rio. "Intolerância religiosa afasta professora de escola na Praça Seca, na Zona Oeste". Jornal O Dia. Disponível em: <http://odia.ig.com.br/noticia/rio-de-janeiro/2015-02-11/intolerancia-religiosa-afasta-professora-de-escola-na-praca-seca-na-zona-oeste.html $>$. Acesso em 02 de julho de 2015.

${ }^{3}$ MELLO, Katia. "Rio tem o $2^{\circ}$ maior números de caso de intolerância religiosa". Jornal $O$ Globo. Disponível em: <http://g1.globo.com/rio-de-janeiro/noticia/2014/09/rj-tem-o-2-maior -numero-de-casos-de-intolerancia-religiosa-do-pais.html>. Acesso em 02 de julho de 2015.

${ }^{4}$ COELHO, Paulino. "Estudo diz que intolerância religiosa aumentou em todo mundo". Radio Renascença. Disponível em $<\mathrm{http}: / /$ rr.sapo.pt/informacao_detalhe.aspx?fid=29\&did=135780>. Acesso em 02 de julho de 2015.

${ }^{5}$ WIESEL, Elie. "A intolerância”. In: BARRET-DUCROCO, Françoise (Org.). Foro Internacional sobre a Intolerância. Rio de Janeiro: Bertrand Brasil, 2000, p. 7.

${ }^{6}$ PRESSE, France. "Franqueza do papa sobre genocídio armênio enfraquece papel da Turquia". Jornal $O$ Globo. Disponível em: <http://g1.globo.com/mundo/noticia/2015/04/franquezado-papa-sobre-genocidio-armenio-enfraquece-papel-da-turquia.html $>$. Acesso em 02 de julho de 2015 .
} 
de é um forte elemento que está presente em várias manifestações e expressões populares. Segundo dados do último censo de 2010, a maioria do país é cristã e está dividida em três principais denominações: católicos, evangélicos de missão e pentecostais?.

A observação do censo religioso ao longo das últimas décadas demonstra que houve uma redução significativa no número de católicos e um aumento das igrejas pentecostais. Percebe-se também uma disposição do indivíduo à experimentação, configurando assim um cenário propício à mobilidade religiosa e a dupla ou tripla pertença ${ }^{8}$. O Brasil está cada vez mais plural no segmento religioso e isso acaba por gerar (no indivíduo) incertezas com relação aquilo que é justo e correto para se viver. Neste sentido, quando o relativismo assume muita intensidade, o absolutismo volta a seduzir e exercer fascínio ${ }^{9}$. Talvez seja por isso, que casos e mais casos de intolerância vêm sendo registrados.

Vale ressaltar que a intolerância religiosa se manifesta intolerante a todo outro/diferente e os profetas da intolerância ${ }^{10}$ utilizam-se da Bíblia para excluir, segregar e expressar um discurso de ódio. Os cristãos, que são alvo de intolerância nos países onde são minoria, são os que aqui promovem a intolerância religiosa. Observa-se que, em termos religiosos, intolerância e poder (representativo) estão de alguma forma relacionados. A maioria oprime uma minoria. A questão, porém, é bem mais complexa, pois no caso do Brasil, os intolerantes são minoria no segmento cristão, contudo tem muita ressonância tanto na mídia quanto na política. A Bancada Evangélica no Congresso Nacional tem 78 membros, está cada vez mais fortalecida e tem a Presidência da Câmara com Eduardo Cunha (PMDB/RJ) ${ }^{11}$.

Assim, faz-se necessário apurar o olhar sobre o foco religião e política pois, pode vir a ser um ponto relevante no aumento da intolerância. O que

7 Disponível em: <http://www.editora.vrc.puc-rio.br/docs/ebook_religiao_e_territorio_no_ brasil_1991-2010.pdf $>$. Acesso em 3 de julho de 2015.

8 Cf. FERNANDES, Silvia. "A (re)construção da identidade religiosa inclui dupla ou tripla pertença". Disponível em: <http://www.ihu.unisinos.br/entrevistas/511249-estamosfalando-de-re-construcao-de-identidade-religiosa-entrevista-especial-com-silvia-fernandes $>$. Acesso em 3 de julho de 2015.

9 Cf. TEIXEIRA, Faustino. "Peter Berger e a religião". Disponível em: <http://fteixeiradialogos.blogspot.com.br/2010/04/peter-berger-e-religiao.html>. Acesso em 03 de julho de 2015 .

${ }^{10}$ Alguns pastores ou representantes evangélicos, arautos do ódio.

${ }^{11}$ Dados início de julho/2015. 
atualmente percebe-se é que muitos deputados querem trocar a Constituição Brasileira pela Bíblia. Isso fere a laicidade do Estado, é um retrocesso e mais, um perigo à democracia e cidadania já conquistadas.

A intolerância religiosa no Brasil é quase uma exclusividade das igrejas neopentecostais ou pentecostais ${ }^{12}$. E geralmente, a palavra de ódio é destinada às religiões de matriz africanas ${ }^{13}$.

Nesta comunicação, faremos uma pequena análise da intolerância religiosa presente no Brasil, depois lançaremos luzes sobre a questão através do Evangelho e por fim, apresentaremos uma proposta de caminhada ecumênica para deslegitimar atitudes intolerantes.

\section{O rosto da intolerância}

Iniciamos este tópico trazendo a afirmativa de Elie Wiesel: "a intolerância não é apenas instrumento fácil do inimigo; ela é o inimigo. Quando a linguagem fracassa, é a violência que a substitui. A violência é também a linguagem da intolerância, que gera o ódio"14.

A frase citada se adequa perfeitamente ao caso da menina de onze anos, do Rio de Janeiro, que recebeu uma pedrada por estar vestida com roupa branca, do Candomblé. No dia catorze de junho, Kailane Campos e familiares saíam de um culto na Penha, subúrbio do Rio de Janeiro, quando foi atingida por uma pedra atirada por dois homens que insultavam o grupo. Segundo a narrativa da avó de Kailane, os homens gesticulavam com a Bíblia nas mãos e chamavam a todos de "diabo", gritavam "vai pro inferno", "Jesus está voltando"15. Houve grande reação acerca deste episódio, manifestações contra a intolerância religiosa, passeata no bairro da Penha, RJ, em prol da tolerância e do diálogo e vários segmentos religiosos se solidarizaram com a menina e a família.

\footnotetext{
12 "Quase”, porque é a que temos informação através de pesquisas e análises sociais e também através de matérias e reportagens. Pode ser que exista intolerância de outros grupos religiosos, mas não é representativo para o estudo realizado aqui.

${ }^{13}$ Contudo não podemos deixar de registrar o episódio do bispo Von Helde, da Igreja Universal do Reino de Deus, que chutou a imagem de Nossa Senhora Aparecida em 12 de outubro de 1995.

${ }^{14}$ WIESEL, Elie. "A intolerância”. In: BARRET-DUCROCO, Françoise (Org.). Foro Internacional sobre a Intolerância. Rio de Janeiro: Bertrand Brasil, 2000, p. 7.

${ }^{15}$ RODRIGUES, Matheus. "Criança vítima de intolerância religiosa se encontra com Dom Orani”. Jornal O Globo. Disponível em: <http://g1.globo.com/rio-de-janeiro/noticia/2015/06/ crianca-vitima-de-intolerancia-religiosa-no-rio-se-encontra-com-dom-orani.html $>$. Acesso em 03 de julho de 2015 .
} 
Dom Orani Tempesta, arcebispo do Rio de Janeiro, convidou Kailane e a família para um café da manhã, do qual participaram o babalaô Ivanir dos Santos e o pastor da Primeira Igreja Batista em Vila da Penha, João de Melo, com o intuito de discutir ações que promovam a paz e a tolerância religiosa. Ressaltamos aqui o esforço tanto do arcebispo do Rio quanto do pastor batista em afirmar o compromisso cristão com a tolerância e o respeito entre as religiões. Os cristãos foram os primeiros beneficiários no Ocidente de uma visão tolerante - O Edito de Milão (também conhecido como Edito da Tolerância), proclamado por Constantino (313), foi a primeira grande declaração de tolerância religiosa, que concedia aos cristãos e a todos os outros a liberdade de seguir sua religião ${ }^{16}$. Segundo Menezes,

O conceito de intolerância tem de ser colocado em sua perspectiva histórica para ganhar o seu relevo próprio. Na verdade a tolerância surgiu historicamente como uma luta contra a intolerância, e, como as lutas contra as discriminações que vieram depois - o movimento negro, o movimento feminista etc. - tem uma atitude clara de militância, não é uma atitude primeira. $E$, antes, uma reação contra uma situação dada; contra a intolerância; $e ́$ a defesa de um direito humano dos mais sagrados; o direito à diferença. Equivale a declarar que o intolerável mesmo é a intolerância. $\dot{E}$ uma reafirmação, uma reposição do sujeito diante da intolerância que quer negá-lo; ao afirmar-se contra sua negação, afirma-se como um direito de ser o que ele é; e nega ao intolerante o direito de negá-lo ${ }^{17}$.

O direito humano à diferença - intolerável é negá-lo. Em pleno século XXI ainda encontramos trabalho escravo, mutilação feminina, preconceitos de todos os tipos e barbáries em nome de Deus.

Como já dito na introdução deste artigo, o principal alvo da intolerância são as religiões de matriz africanas - Umbanda e Candomblé. Vários centros umbandistas vêm reforçando a segurança com câmeras, alarmes, sensores de movimento, cadeados e outros equipamentos de proteção. A Lei $n^{\circ}$ 7.437, ou Lei Caó, no seu artigo 20, prevê uma pena de multa e

${ }^{16}$ ALTMAN, Max. "Hoje na história-Constantino promulga Édito de Milão". Operamundi. Disponível em: <http:/operamundi.uol.com.br/conteudo/historia/35649/hoje+na+historia $+313++$ constantino+promulga + edito + de + milao.shtml $>$. Acesso em 10 de out 2016.

${ }^{17}$ MENEZES, Paulo. "Tolerância e religiões". In: TEIXEIRA, F. (Org.). O diálogo inter-religioso como afirmação da vida. São Paulo: Paulinas, 1997, p. 42 (39-54). 
reclusão de um a três anos para quem praticar, induzir ou incitar a discriminação ou preconceito de raça, cor, etnia, religião ou procedência nacional.

Vários segmentos da sociedade, como ONGs, coletivos, grupos de defesa dos direitos humanos, associações religiosas, entre outros estão sensibilizados e atentos à questão da crescente intolerância. Há grupos que se articulam em prol da promoção da paz, e muitas vezes adquirem um veio profético junto à sociedade quando denunciam as injustiças das estruturas sociais ${ }^{18}$.

\section{A fúria neopentecostal}

A intolerância presente nas igrejas neopentecostais tem sido tema de vários estudos ${ }^{19}$. A fúria se estende do púlpito às mídias: televisão, internet, jornais, rádios, etc. Os principais alvos são as entidades do panteão afro-brasileiro como exus e pombas giras que foram associados à figura do diabo cristão. Baseados na leitura de 1Jo 3,8 - "Para isto se manifestou o Filho de Deus: para destruir as obras do diabo" - os seguidores de Jesus Cristo deveriam dar continuidade à obra do Messias. Neste sentido, é frequente sessões de exorcismos nas igrejas, testemunhos de conversão, reconstituições de casos reais ${ }^{20}$. "Insuflados por essas crenças, os membros das igrejas neopentecostais muitas vezes invadem terreiros visando destruir altares, a quebrar imagens e a "exorcizar" seus frequentadores, o que geralmente termina em agressão física" "21. Neste universo de intolerância, há também os ataques aos símbolos e a absorção/incorporação de elementos da cultura africana, como

\footnotetext{
${ }^{18}$ Como exemplo, trazemos a ONG Rio de Paz, http://www.riodepaz.org.br, fundada em janeiro de 2007 com o objetivo de dar voz aos que não tem voz e visibilidade aos invisíveis. Tem como missão ser agente de redução das violações dos direitos humanos por meio de ações pacíficas e criativas que mobilizem sociedade e poder público.

${ }^{19}$ SILVA, Wagner Gonçalves da (Org.). Intolerância religiosa: impactos do neopentecostalismo no campo religioso afro-brasileiro. São Paulo: EDUSP, 2007.

${ }^{20}$ SILVA, Wagner Gonçalves da. "Os ataques neopentecostais às religiões afro-brasileiras e aos símbolos da herança africana no Brasil”. In: SILVA, Wagner Gonçalves da (Org.). Intolerância religiosa: impactos do neopentecostalismo no campo religioso afro-brasileiro. São Paulo: EDUSP, 2007, p. 11.

${ }^{21}$ SILVA, Wagner Gonçalves da. "Os ataques neopentecostais às religiões afro-brasileiras e aos símbolos da herança africana no Brasil”. In: SILVA, Wagner Gonçalves da (Org.). Intolerância religiosa: impactos do neopentecostalismo no campo religioso afro-brasileiro. São Paulo: EDUSP, 2007, p. 12.
} 
por exemplo, a capoeira de Cristo ou o acarajé do Senhor - há uma pretensão em dissociar tanto a prática da capoeira quanto o alimento acarajé dos seus ancestrais africanos ${ }^{22}$.

No caso da IURD, o pastor além de reconhecer as entidades da cultura afro, mostra ao fieis que ele tem poder sobre elas - exorciza a pessoa, expulsa o "demônio". Algo semelhante com o que ocorria na Idade Média com o catolicismo e os acusados de feitiçaria ${ }^{23}$. O bispo Edir Macedo (IURD) lançou em 1988 o livro Orixás, caboclos \& guias. Deuses ou demônios? que foi motivo de processo judicial mas acabou sendo liberado, tendo uma grande tiragem.

$\mathrm{O}$ ataque às religiões afro-brasileiras, mais do que uma estratégia de proselitismo junto às populações de baixo nível socioeconômico, potencialmente consumidoras dos repertórios religiosos afrobrasileiros e neopentecostais, é consequência do papel que as mediações mágicas e a experiência do transe religioso ocupam na própria dinâmica do sistema neopentecostal em contato com o repertório afro-brasileiro. O desenvolvimento recente do catolicismo carismático atestaria a demanda crescente por tais mediações também nesse segmento religioso majoritário. No Brasil, enquanto os processos de secularização e racionalização atingiam os setores cristãos (catolicismo, protestantismo histórico etc.), o pentecostalismo surgiu como uma possibilidade, ainda tímida na primeira e segunda fases, mas muito forte na terceira, de valorização da experiência do avivamento religioso. No neopentecostalismo, essa característica radicaliza-se em termos de transformá-la em uma religião da experiência vivida no próprio corpo, característica que tradicionalmente esteve sob a hegemonia das religiões afro-brasileiras e do espiritismo kardecista. Combater essas religiões pode ser, portanto, menos uma estratégia proselitista voltada para retirar fiéis deste segmento embora tenha esse efeito - e mais uma forma de atrair fiéis ávidos pela experiência de religiões com forte apelo mágico, extáticas,

\footnotetext{
${ }^{22}$ SILVA, Wagner Gonçalves da. "Os ataques neopentecostais às religiões afro-brasileiras e aos símbolos da herança africana no Brasil”. In: SILVA, Wagner Gonçalves da (Org.). Intolerância religiosa: impactos do neopentecostalismo no campo religioso afro-brasileiro. São Paulo: EDUSP, 2007, pp. 15-16.

${ }^{23}$ ORO, Ari Pedro. "Intolerância religiosa iurdiana e reações afro no Rio Grande do Sul”. In: SILVA, Wagner Gonçalves da (Org.). Intolerância religiosa: impactos do neopentecostalismo no campo religioso afro-brasileiro. São Paulo: EDUSP, 2007, p. 37.
} 
com a vantagem da legitimidade social conquistada pelo campo religioso cristão ${ }^{24}$.

No âmbito desta comunicação, não nos compete analisar e elencar todos os estudos já realizados sobre neopentecostalismo e intolerância; destacamos algumas questões que consideramos mais pertinentes para a esfera teológica como a utilização da Bíblia na interpretação da passagem - 1Jo 3,8 - [1]e a exploração da imagem do demônio identificando-o com as deidades de outras tradições religiosas[2]. Estas duas questões nos ajudam a compreender a (fraca) fundamentação teológica que poderia vir a "justificar" a atitude intolerante de membros de igrejas neopentecostais. Logicamente, há uma guerra de mercado e por fieis, bem como o envolvimento de pastores na esfera política; e, embora compreender estes fatores seja importante para a promoção de uma cultura de paz, por ora, não poderão ser contemplados neste artigo.

\section{A prática do amor radical}

Em uma sociedade pluralista e neoliberal, a teologia deve buscar caminhos que promovam a boa convivência humana, a prática de uma cidadania consciente, a inclusão dos marginalizados e a justiça como um bem comum. Contudo, deve também estar conectada à fonte, à tradição, aos Evangelhos e a Jesus Cristo. Assim, estará sendo fiel a sua essência podendo contribuir para a construção de relações mais humanizadas, comunicando a Boa Nova, fazendo diferença em um mundo que é ameaçado pela indiferença ou o ódio ao outro ${ }^{25}$.

Os Evangelhos são uma excelente fonte de inspiração para ação cristã. Neles podemos encontrar a ética de Jesus Cristo, muito mais relevante do que passagens descontextualizadas.

${ }^{24}$ SILVA, Vagner Gonçalves da. "Neopentecostalismo e religiões afro-brasileiras: Significados do ataque aos símbolos da herança religiosa africana no Brasil contemporâneo". Mana 1 (2007), pp. 207-236. Disponível em: $<$ http://www.scielo.br/scielo.php?script=sci_arttext\&pi$\mathrm{d}=\mathrm{S} 0104-93132007000100008 \& \operatorname{lng}=\mathrm{en} \& \mathrm{nrm}=\mathrm{iso}>$. Acesso em 14 julho de 2015 .

25 “A indiferença é marca de um tempo que já não tem espaço para o outro; de um sem-tempo do outro, cheio do mesmo. A diferença é marco de uma compreensão plural do humano e de sua realização. Ser é ser diferente, ser diferente é não-ser o mesmo. A mesmice preenche; a alteridade abre (-se). Como somente se pode construir e se construir na abertura, é a alteridade que abriga o humano como construção do ser humano, mais humano". CARBONARI, Paulo César. "Sujeito de direitos humanos". In: Ministério da Educação. Educação em direitos humanos: fundamentos teórico-metodológicos. 2007. Disponível em: $<$ http://memoriaenelmercosur.educ. ar/wp-content/uploads/2010/04/cap2artigo4.pdf $>$. Acesso em 16 de julho de 2015. 
O primeiro ponto que destacamos é a radical solidariedade de Jesus Cristo com o diferente. Jesus ouve o pedido do centurião romano (Mt 8, 5-13; Lc 7,1-10). A presença dos soldados romanos no território dos judeus era uma afronta à dignidade do povo, símbolo maior da opressão de Roma aos territórios conquistados. O centurião era comandante e reconhecia a autoridade de Jesus, era homem de bem - edificou a sinagoga dos judeus (Lc 7,5) - e de fé e daí decorre toda uma hermenêutica da narrativa. Mas o que realçamos aqui é a radicalidade da atenção que Jesus disponibiliza ao outro, que é o opressor. Jesus não vê o opressor como uma categoria sociológica, nem com indiferença ou mesmo ódio, vê o ser humano, o sofrimento, a dor e se compadece - Mt 8,7; Lc 7,6. Na ação de Jesus prevalece seu ensinamento "amai vossos inimigos" (Mt 5,44). Tolerância? Não, a radicalidade da ação de Jesus nos indica seu comprometimento com a pessoa humana através da solidariedade e da compaixão. Os judeus eram proibidos pela lei de ter contato pessoal com pessoas de outras nações (At 10,28), mas a lei judaica nunca foi impedimento para a prática compassiva e solidária de Jesus como também vemos em Mc 2,27 - a cura no dia de sábado. Como Filho de Deus, Jesus Cristo era radicalmente amoroso com o ser humano. O princípio da vida prevalecia sobre o princípio de lei quando as interpretações desta produziam exclusão ou injustiça.

Também São Paulo enfatiza a caridade para com todas as pessoas, a construção da paz e uma convivência em harmonia mesmo com o diferente (Rm 12, 14-21).

Não podemos esquecer que bem-aventurados são os pacificadores, pois serão chamados de filhos de Deus (Mt 5,9). Aqueles que constroem a paz são elevados à condição de filhos de Deus, título referido a Jesus Cristo.

Dentro do contexto do Novo Testamento - e da perícope onde está inserida o versículo 1 Jo 3,8 - a utilização dessa passagem para justificar ataques a qualquer religião ou "demônio" é absurdamente abusiva. Os "filhos do diabo" são justamente aqueles que não praticam a justiça e não amam a seu irmão $(1 \mathrm{Jo} 3,10)^{26}$.

\footnotetext{
${ }^{26}$ É notório os muitos escândalos envolvendo pastores neopentecostais que praticamente extorquem os fiéis através do dízimo. O jornalista Ricardo Boechat respondeu à provocação do pastor Silas Malafaia com um discurso contundente que foi amplamente compartilhado nas redes sociais. Cf. BOECHAT, Ricardo. "Boechat responde a Silas Malafaia na Band News FM". Disponível em: <https://www.youtube.com/watch?v=IP0CLLJIe9o>. Acesso em 10 de julho de 2015 .
} 
É inadmissível que cristãos sejam intolerantes ao próximo. A prática e os ensinamentos de Jesus não comportam essa atitude por parte de seus seguidores. Diante da pluralidade cristã, afirmamos as palavras do Concílio Vaticano II: "nas coisas necessárias haja unidade, nas dúbias e incertas liberdades, mas, em todas, caridade" 27 .

A prática de algumas igrejas neopentecostais é claramente ofensiva às religiões afro-brasileiras, incitando ao ódio e a violência. Esta atitude, além de desrespeitar os mandamentos cristãos, ainda é contrária à Declaração de Direitos Humanos, cujo artigo 18 afirma que "toda pessoa tem direito à liberdade de pensamento, consciência e religião; este direito inclui a liberdade de mudar de religião ou crença e a liberdade de manifestar essa religião ou crença, pelo ensino, pela prática, pelo culto e pela observância, isolada ou coletivamente, em público ou em particular" ${ }^{28}$ e à Constituição Brasileira, que no seu artigo $5^{\circ}$ garante o direito à liberdade religiosa.

Neste contexto de conflito, faz-se necessário pensar medidas que possam deslegitimar atitudes de intolerância, contudo é imprescindível que o segmento cristão seja protagonista, repudiando clara e abertamente o discurso de alguns pastores e a conduta praticada por membros de igrejas neopentecostais.

\section{Conclusão: Unidade na caridade}

Não é mais possível aceitar atitudes intolerantes por parte de alguns pastores e fieis das igrejas neopentecostais. Esta prática fere a doutrina cristã e estimula o confronto que geralmente termina em violência.

Necessário reconhecer que, a partir desse cenário, os cristãos devem realizar uma (nova) conversão para conviver com outras religiões e buscar a unidade apregoada por Jesus Cristo (Jo 17,21). É urgente que possamos pensar no ecumenismo como uma forma de combater a violência de alguns grupos cristãos. A unidade dos cristãos é um princípio fundamental que pode deslegitimar atitudes intolerantes do próprio segmento cristão.

\footnotetext{
${ }^{27}$ CONSTITUIÇÃO LUMEN GENTIUM. Vaticano II: mensagens, discursos e documentos. 2. ed. São Paulo: Paulinas, 2007, p. 547, n. 1639.

28. ORGANIZAÇÃO DAS NAÇÕES UNIDAS. "Declaração Universal dos Direitos Humanos, resolução no $217^{a}$ da Assembleia Geral das Nações Unidades em 10 de dezembro de 1948". Disponível em: <http://www.direitoshumanos.usp.br/index.php/Declara\%C3\%A7\%C3\%A3o -Universal-dos-Direitos-Humanos/declaracao-universal-dos-direitos-humanos.html>. Acesso em 21 de julho de 2015.
} 
$\mathrm{O}^{\mathrm{CONIC}}{ }^{29}$ apresenta o documento Testemunho cristão num mundo de pluralismo religioso -elaborado conjuntamente pelo Conselho Mundial de Igrejas, o Pontifício Conselho para o Diálogo Inter-Religioso e a Aliança Evangélica Mundial - que traz muitas luzes para a ação cristã ${ }^{30}$. Enfaticamente, o documento pede:

\begin{abstract}
Construam relações de respeito e confiança com pessoas de todas as religiões, particularmente em nível institucional entre Igrejas e outras comunidades religiosas, envolvendo-se em contínuo diálogo inter-religioso como parte de seu compromisso cristão [...], o diálogo inter-religioso pode proporcionar novas oportunidades para a resolução de conflitos, a restauração da justiça, a cura de memórias, a reconciliação e a construção da paz. [...]. Os cristãos devem evitar interpretações equivocadas das crenças e práticas das pessoas de religiões diferentes ${ }^{31}$.
\end{abstract}

Neste sentido, é importante a participação em movimentos que visibilizem a expressão da tolerância cristã como a Caminhada em Defesa da Liberdade Religiosa que ocorre no mês de setembro no Rio de Janeiro, por exemplo, bem como a formação/evangelização/educação para tolerância.

A formação dos leigos é fundamental para se estabelecer uma cultura de paz social e inter-religiosa. As igrejas cristãs precisam educar para a tolerância. Isso deve ser assumido como um compromisso maior, tendo como fun-

\footnotetext{
${ }^{29}$ Conselho Nacional de Igrejas Cristãs no Brasil. Atualmente fazem parte do CONIC 5 igrejasmembros - Igreja Católica Apostólica Romana (ICAR), Igreja Episcopal Anglicana do Brasil (IEAB), Igreja Evangélica de Confissão Luterana no Brasil (IECLB), Igreja Sirian Ortodoxa no Brasil (ISOA) e Igreja Presbiteriana Unida (IPU) - e 9 membros fraternos - Coordenadoria Ecumênica de Serviço (CESE), Koinonia Presença Ecumênica e Serviço, Centro Ecumênico de Serviços à Evangelização e Educação Popular, Centro de Estudos Bíblicos (CEBI), Comissão Nacional de Combate ao Racismo (CENACORA), Ação dos Cristãos para a Abolição da Tortura (ACAT - Brasil), Dia Mundial de Oração (DMO), Programa de Formação e Educação Comunitária (PROFEC), Centro Ecumênico de Capacitação e Assessoria (CECA).

30 "Conscientes das tensões entre pessoas e comunidades de convicções religiosas diferentes e da diversidade de interpretações do testemunho cristão, o Pontifício Conselho para o Diálogo Inter-religioso (PCDI), o Conselho Mundial de Igrejas (CMI) e, a convite do CMI, a Aliança Evangélica Mundial (AEM), promoveram vários encontros num período de cinco anos com intuito de refletir e produzir o presente documento que apresenta um conjunto de recomendações sobre a maneira de pôr em prática o testemunho cristão no mundo". CONIC. "Testemunho cristão num mundo de pluralismo religioso". Disponível em: <http://conic.org.br/portal/files/ recomendacoes_CMI.pdf $>$. Acesso em 22 de julho de 2015.

${ }^{31}$ CONIC. "Testemunho cristão num mundo de pluralismo religioso". Disponível em: $<$ http:// conic.org.br/portal/files/recomendacoes_CMI.pdf>. Acesso em 22 de julho de 2015.
} 
damento a própria pessoa de Jesus Cristo. Promover o bem comum envolve participar das mediações que encontramos na sociedade - associações, órgãos públicos e privados, ONGs, instituições, universidades - assumindo a postura e compromisso de diálogo, respeito e tolerância.

O testemunho cristão deveria ser exemplo de respeito e de diálogo, a verdadeira caridade é servir com humildade. Tem circulado nas redes sociais um post com os seguintes dizeres: "é preciso evangelizar os evangélicos" (entendendo aqui "evangélicos" como todos aqueles que seguem a Bíblia, incluindo os católicos). E por que isto está circulando? Porque a imagem dos cristãos de hoje é semelhante a dos antigos fariseus do tempo de Jesus - hipócritas.

É necessário que possamos rever nossas atitudes, assumir com humildade as nossas limitações, e realizar uma verdadeira conversão para que possamos promover uma cultura de paz, de tolerância e de solidariedade.

O intolerável é a intolerância que parte das igrejas cristãs. Realizar, de fato, um ecumenismo prático talvez seja uma perspectiva para o desarmamento e para a construção do bem comum em uma sociedade plural.

\section{Referências bibliográficas}

ALTMAN, Max. "Hoje na história-Constantino promulga Édito de Milão". Operamundi. Disponível em: <http://operamundi.uol.com.br/conteudo/ historia/35649/hoje+na+historia $+313++$ constantino + promulga + edito+de+milao.shtml $>$. Acesso em 10 de outubro de 2016.

BOECHAT, Ricardo. "Boechat responde a Silas Malafaia na Band News FM". Disponível em: <https://www.youtube.com/watch?v=IP0CLLJIe9o>. Acesso em 10 de julho de 2015.

CARBONARI, Paulo César. "Sujeito de direitos humanos". In: Ministério da Educação. Educação em direitos humanos: fundamentos teórico-metodológicos 2007. Disponível em: <http://memoriaenelmercosur.educ.ar/ wp-content/uploads/2010/04/cap2artigo4.pdf>. Acesso em 16 de julho de 2015.

COELHO, Paulino. "Estudo diz que intolerância religiosa aumentou em todo mundo". Radio Renascença. Disponível em: <http://rr.sapo.pt/informacao_detalhe.aspx?fid=29\&did=135780 $>$. Acesso em 02 de julho de 2015. 
CONIC. "Testemunho cristão num mundo de pluralismo religioso". Disponível em: <http://conic.org.br/portal/files/recomendacoes_CMI.pdf $>$. Acesso em 22 de julho de 2015.

CONSTITUIÇÃO LUMEN GENTIUM. Vaticano II: mensagens, discursos e documentos. 2. ed. São Paulo: Paulinas, 2007.

FERNANDES, Silvia. "A (re)construção da identidade religiosa inclui dupla ou tripla pertença". Disponível em: <http://www.ihu.unisinos.br/ entrevistas/511249-estamos-falando-de-re-construcao-de-identidadereligiosa-entrevista-especial-com-silvia-fernandes $>$. Acesso em 3 de julho de 2015.

MELLO, Katia. "Rio tem o $2^{\circ}$ maior números de caso de intolerância religiosa". Jornal O Globo. Disponível em: <http://g1.globo.com/rio-de-janeiro/ noticia/2014/09/rj-tem-o-2-maior-numero-de-casos-de-intoleranciareligiosa-do-pais.html $>$. Acesso em 02 de julho de 2015.

MENEZES, Paulo. "Tolerância e religiões". In: TEIXEIRA, F. (Org.). O diálogo inter-religioso como afirmação da vida. São Paulo: Paulinas, 1997.

ORGANIZAÇÃO DAS NAÇÕES UNIDAS. "Declaração Universal dos Direitos Humanos, resolução $\mathrm{n}^{\circ} 217^{\mathrm{a}}$ da Assembleia Geral das Nações Unidades em 10 de dezembro de 1948". Disponível em: <http://www. direitoshumanos.usp.br/index.php/Declara\%C3\%A7\%C3\%A3oUniversal-dos-Direitos-Humanos/declaracao-universal-dos-direitoshumanos.html>. Acesso em 21 de julho de 2015.

ORO, Ari Pedro. "Intolerância religiosa iurdiana e reações afro no Rio Grande do Sul”. In: SILVA, Wagner Gonçalves da (Org.). Intolerância religiosa: impactos do neopentecostalismo no campo religioso afro-brasileiro. São Paulo: EDUSP, 2007.

PRESSE, France. "Franqueza do papa sobre genocídio armênio enfraquece papel da Turquia". Jornal O Globo. Disponível em: <http://g1.globo. $\mathrm{com} / \mathrm{mundo} /$ noticia/2015/04/franqueza-do-papa-sobre-genocidioarmenio-enfraquece-papel-da-turquia.html $>$. Acesso em 02 de julho de 2015.

RODRIGUES, Matheus. "Criança vítima de intolerância religiosa se encontra com Dom Orani”. Jornal O Globo. Disponível em: <http://g1.globo. 
com/rio-de-janeiro/noticia/2015/06/crianca-vitima-de-intoleranciareligiosa-no-rio-se-encontra-com-dom-orani.html $>$. Acesso em 03 de julho de 2015.

SANT'ANNA, Emilio. "A cada 3 dias, governo recebe uma denúncia de intolerância religiosa”. Jornal Folha de São Paulo. Disponível em: $<$ http://www1.folha.uol.com.br/cotidiano/2015/06/1648607-a-cada-3dias-governo-recebe-uma-denuncia-de-intolerancia-religiosa.shtml $>$. Acesso em 02 de julho de 2015.

SEÇÃO Rio. "Intolerância religiosa afasta professora de escola na Praça Seca, na Zona Oeste". Jornal O Dia. Disponível em: $<$ http://odia.ig.com. br/noticia/rio-de-janeiro/2015-02-11/intolerancia-religiosa-afastaprofessora-de-escola-na-praca-seca-na-zona-oeste.html>. Acesso em 02 de julho de 2015.

SILVA, Wagner Gonçalves da (Org.). Intolerância religiosa: impactos do neopentecostalismo no campo religioso afro-brasileiro. São Paulo: EDUSP, 2007.

SILVA, Vagner Gonçalves da. "Neopentecostalismo e religiões afro-brasileiras: Significados do ataque aos símbolos da herança religiosa africana no Brasil contemporâneo". Mana 1 (2007), pp. 207-236. Disponível em: <http://www.scielo.br/scielo.php?script=sci_arttext\&pid=S0104$93132007000100008 \& \operatorname{lng}=$ en\&nrm=iso $>$. Acesso em 14 de julho de 2015.

SILVA, Wagner Gonçalves da. "Os ataques neopentecostais às religiões afro-brasileiras e aos símbolos da herança africana no Brasil". In: SILVA, Wagner Gonçalves da (Org.). Intolerância religiosa: impactos do neopentecostalismo no campo religioso afro-brasileiro. São Paulo: EDUSP, 2007, pp. 15-16.

TEIXEIRA, Faustino. "Peter Berger e a religião". Disponível em: $<$ http:// fteixeira-dialogos.blogspot.com.br/2010/04/peter-berger-e-religiao. html >. Acesso em 03 de julho de 2015.

WIESEL, Elie. “A intolerância”. In: BARRET-DUCROCO, Françoise (Org.). Foro Internacional sobre a Intolerância. Rio de Janeiro: Bertrand Brasil, 2000, p. 7. 
Mônica Baptista Campos

Mestre em Teologia pela PUC-Rio Professora do Departamento de Teologia da PUC-Rio, setor de Cultura Religiosa Editora da Revista CREatividade Rio de Janeiro / RJ - Brasil E-mail: monica.b.c@uol.com.br

Recebido em: 17/10/15 Aprovado em: 05/04/16 